\title{
Fish population persistence in hydrologically variable landscapes
}

\author{
Nick R. Bond, ${ }^{1,4}$ Stephen R. Balcombe, ${ }^{1}$ David A. Crook, ${ }^{2,5}$ Jonathan C. Marshall, ${ }^{1,3}$ Norbert Menke, ${ }^{3}$ \\ AND JAYE S. LOBEGEIGER ${ }^{3}$ \\ ${ }^{1}$ Australian Rivers Institute, Griffith University, Nathan, Queensland 4111 Australia \\ ${ }^{2}$ Arthur Rylah Institute for Environmental Research, Department of Sustainability and Environment, Heidelberg, \\ Victoria 3086 Australia \\ ${ }^{3}$ Department of Science, Information Technology, Innovation and the Arts, Dutton Park, Queensland 4102 Australia
}

\begin{abstract}
Forecasting population persistence in environments subjected to periodic disturbances represents a general challenge for ecologists. In arid and semiarid regions, climate change and human water use pose significant threats to the future persistence of aquatic biota whose populations typically depend on permanent refuge waterholes for their viability. As such, habitats are increasingly being lost as a result of decreasing runoff and increasing water extraction. We constructed a spatially explicit population model for golden perch Macquaria ambigua (Richardson), a native freshwater fish in the Murray-Darling Basin in eastern Australia. We then used the model to examine the effects of increased aridity, increased drought frequency, and localized human water extraction on population viability. Consistent with current observations, the model predicted golden perch population persistence under the current climate and levels of water use. Modeled increases in local water extraction greatly increased the risk of population decline, while scenarios of increasing aridity and drought frequency were associated with only minor increases in this risk. We conclude that natural variability in abundances and high turnover rates (extinction/recolonization) of local populations dictate the importance of spatial connectivity and periodic cycles of population growth. Our study also demonstrates an effective way to examine population persistence in intermittent and ephemeral river systems by integrating spatial and temporal dynamics of waterhole persistence with demographic processes (survival, recruitment, and dispersal) within a stochastic modeling framework. The approach can be used to help understand the impacts of natural and anthropogenic drivers, including water resource development, on the viability of biota inhabiting highly dynamic environments.
\end{abstract}

Key words: climate change; drought; dryland rivers; golden perch; intermittent streams; Macquaria ambigua; metapopulation; Murray-Darling Basin, Australia; population viability analysis; waterholes; water planning.

\section{INTRODUCTION}

Understanding the persistence of populations in patchy and variable environments is a key challenge for basic and applied ecology, both in terms of understanding the processes that promote persistence, but also the likely impacts of changing disturbance regimes. Dryland rivers (i.e., those flowing through arid and semiarid regions) are among the most variable environments in the world, draining roughly $40 \%$ of the global landmass and experiencing only intermittent runoff (Puckridge et al. 2000, Walker et al. 2006, Falke et al. 2010). Such rivers are highly variable in terms of discharge and frequently contract to isolated waterholes that become critical refuges for aquatic biota (Puckridge et al. 1998). The ability for species to persist in these rivers can depend strongly on their ability to tolerate

Manuscript received 26 August 2014, accepted 4 November 2014. Corresponding Editor: R. S. King.

${ }^{4}$ E-mail: n.bond@griffith.edu.au

5 Present address: Charles Darwin University, Darwin, Northern Territory 0815 Australia. harsh environmental conditions within isolated refuges, coupled with high fecundity and dispersal rates to facilitate recolonization during periods of connectivity (e.g., Magoulick and Kobza 2003, Crook et al. 2010).

Increasingly, however, the persistence of dryland river biota is being threatened by the growing issue of water scarcity (Falke et al. 2010). In many regions, human water demands, especially for irrigation, have given rise to high levels of water extraction from rivers and groundwater sources in dryland regions (Sheldon et al. 2002). At a global scale, climate-change induced intensification of the hydrologic cycle is further expected to increase aridity in many dryland ecosystems, and droughts are expected to become more frequent (Dai 2011).

Estimating the impacts of hydrologic changes on biota is made difficult by the fact that many taxa persist within regional metapopulations, where persistence is governed by links between local populations via dispersal (Labbe and Fausch 2000, Perry and Bond 2009). Such spatial population structuring can easily give rise to highly nonlinear population dynamics, 
making it difficult to foresee potentially critical thresholds of habitat loss or isolation (Wilcox et al. 2006).

Dryland rivers are common within the inland catchments of Australia and are recognized as having some of the most variable flow regimes in the world (Puckridge et al. 1998). Associated with this are plant and animal assemblages that rely heavily on refuge waterholes to persist during extended dry periods and are renowned for their boom and bust cycles (Arthington et al. 2005, Sternberg et al. 2011). Waterholes in most of these rivers are subjected to water extraction (via pumping), sometimes for irrigation, but more often to supply water for stock and domestic use (CSIRO 2008b).

We developed a spatially explicit population model to examine the impacts of changing water availability on the population dynamics and persistence of a native fish species. We focused on golden perch, Macquaria ambigua (Richardson, 1845), in the Moonie River in the northern Murray-Darling Basin. Golden perch is a large, native percichthyid fish that is common and widespread in the northern Murray-Darling and neighboring Lake Eyre Basin systems. Golden perch is the primary apex fish predator in the region, and frequently accounts for a large proportion of the overall fish biomass in refuge waterholes (Balcombe et al. 2006). Recent genetic studies of golden perch in the Moonie River reveal high levels of population connectivity punctuated by frequent population bottlenecks, suggesting dispersal among local populations helps regulate long-term persistence of the regional population (Huey et al. 2011).

In developing the model, we draw on several recent empirical data sets describing the movement and demographics of golden perch in the Moonie River and the influence of flow variability on the size and persistence of refuge waterholes. We then use the model to examine three potential threats to waterhole persistence: regional increases in the extent of annual drying (aridity), increases in the frequency of extreme dry years (droughts), and threats associated with localized waterhole drying from both excessive pumping for irrigation and the taking of water for stock and domestic purposes. As well as providing useful information on population viability for this system, our work serves to demonstrate a modeling approach that could readily be applied to a range of other questions (or taxa) regarding population persistence in desert rivers, as well as contributing to our broader understanding of the role that disturbance regimes play in regulating metapopulation persistence in highly dynamic landscapes (e.g., Wilcox et al. 2006, Elkin and Possingham 2008).

\section{Methods \\ Study area}

The Moonie River catchment is located in the northern Murray-Darling Basin and drains an area of $\sim 14870 \mathrm{~km}^{2}$ (Fig. 1). The catchment experiences low annual rainfall $(500-600 \mathrm{~mm} / \mathrm{yr})$, high interannual rainfall variability, and high evaporative losses (1800$2200 \mathrm{~mm} / \mathrm{yr}$; CSIRO 2008b). This climate gives rise to highly intermittent streamflow characterized by long periods with no flow $(198 \pm 14 \mathrm{~d}$, mean $\pm \mathrm{SE}$; maximum 701 d; Fig. 2). Periodic drought cycles further add to the extremes in flow intermittency, and for most of the year, the river exists as a series of isolated waterholes that act as refuges for aquatic biota (see Plate 1). The location and bathymetry of waterholes in some sections of the Moonie River have been mapped using a mix of aerial mapping and boat surveys. Where waterhole data was incomplete, either due to lack of any survey or emphasis on mapping larger waterholes only, data from surveyed sections was used to generate semi-random waterhole locations (including their size and depth), such that the unsurveyed reaches shared the same longitudinal distribution and size-frequency structure of waterholes as the surveyed reaches (Queensland Government, unpublished data). In total, there were 77 waterholes in the modeled river network, 32 of which were considered shallow, and therefore were expected to dry out during drought years (see Methods: Environmental stochasticity for details on how shallow and deep waterholes were each affected by the different disturbances).

\section{Modeling approach}

We developed a spatial population model in which individual waterholes were treated as local populations. The dynamics of each local population were modeled using a female-only, stochastic age-structured matrix model, reflecting survival $(S)$ and fecundity $(F)$. Local populations were connected by dispersal to account for immigration and emigration into and away from individual waterholes during the wet season. Dispersal rates were modeled as a function of waterhole isolation. The local carrying capacity $(k)$ of individual populations was varied spatially and temporally as a function of waterhole size. The model further accounted for variation in vital rates $(S, F)$ and carrying capacity $(k)$ due to the effects of both background environmental fluctuations (normal interannual hydrologic variability) and local and regional disturbances from waterhole pumping and drought, respectively.

The model was constructed using RAMAS Metapop (Akçakaya 2005), which has been widely used to model metapopulation dynamics in terrestrial and aquatic ecosystems (Root 1998, Akçakaya et al. 1999, 2003). RAMAS has the capacity to include the effects of various disturbance regimes (referred to as catastrophes within the RAMAS framework). We included both local (waterhole pumping) and regional (drought) catastrophes in the model, as well as the effects of increasing aridity.

The effect of each scenario on golden perch populations was assessed by considering three primary population measures: the median metapopulation size 


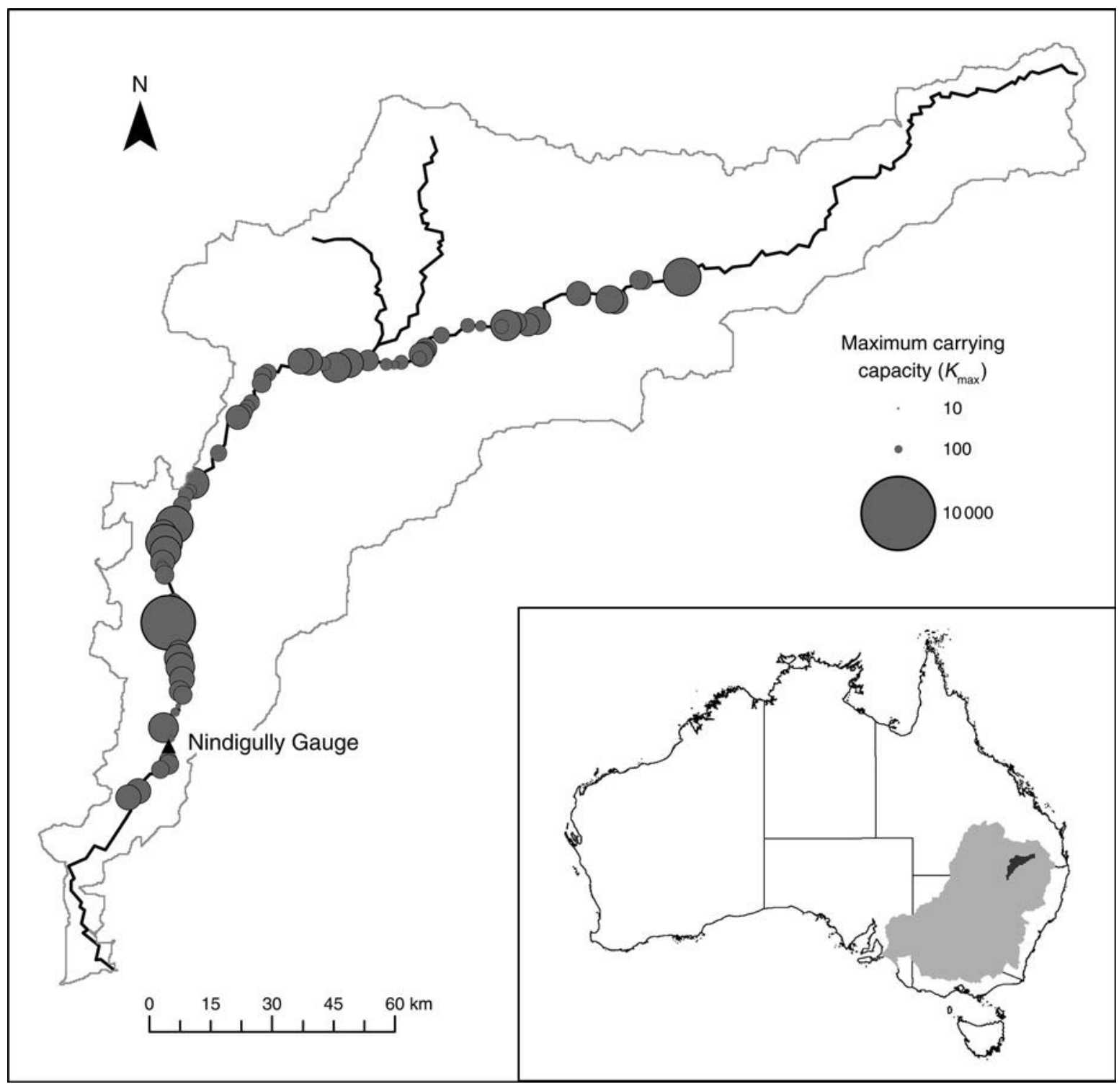

FIG. 1. Map of the Moonie River catchment showing the location of major waterholes and their approximate maximum carrying capacity $\left(k_{\max }\right.$; golden perch/waterhole). The inset map shows the location of the Moonie catchment relative to the Murray-Darling Basin and the Australian continent.

under each scenario, average patch occupancy (number of waterholes occupied), which would likely fall if dispersal and recolonization rates and local recruitment were insufficient to balance rates of local population loss (e.g., from waterhole pumping), and quasi-extinction risk (arbitrarily set at the whole metapopulation falling below 100 individuals within the modeled time interval).

\section{Demographic parameters}

Golden perch are both highly fecund and highly mobile (Pusey et al. 2004). Floods appear to enhance survival and growth of young fish but are not required for spawning (Balcombe et al. 2006, Sternberg et al. 2011). The stage matrices employed in the present analysis assumed similar fecundity patterns across all years.

Vital rates.-Demographic parameter estimates were derived from an analysis of length-frequency data for golden perch collected from the Moonie River during the austral spring from 2006 to 2010, using three fyke nets ( $T$ \& L Netmaking, Mooroolbark, Victoria, Australia) per site (Huey et al. 2011, Sternberg et al. 2011). These data were converted to age-frequency data on the basis of a regression of age against length from a subset of fish collected as part of another study in an adjacent tributary of the Darling, from which otoliths were removed and aged (N. Menke et al., unpublished data; Eq. 1). Because fish are not always sexed during 
a) Daily hydrograph
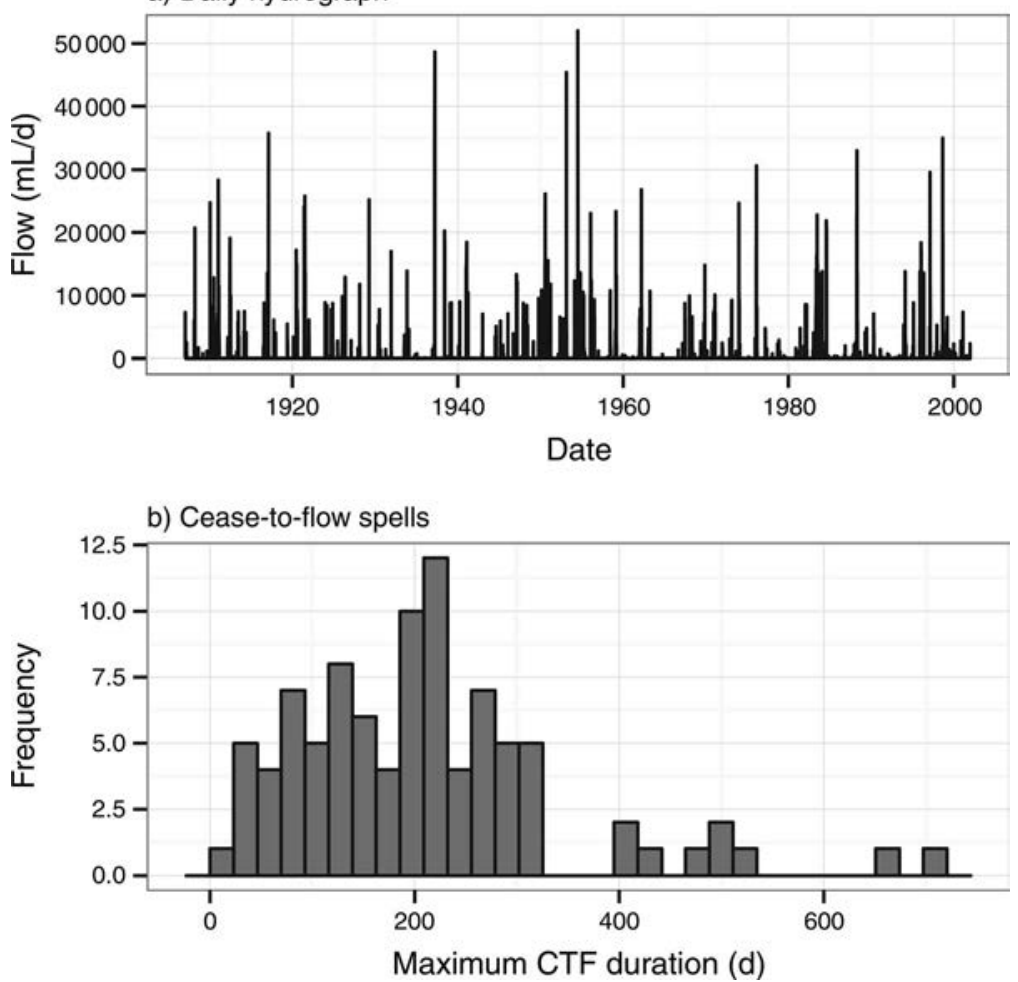

FIG. 2. Summary of streamflow patterns showing (a) daily streamflow time series and (b) frequency distribution of the longest cease-to-flow (CTF) spell at the Nindigully gauge (Gauge No. 417201B; see map in Fig. 1). Note that some spells extend for more than $365 \mathrm{~d}$.

these surveys, male and female growth and survival rates were presumed equal in this analysis. We then based the model structure on the observed age distribution, with seven age classes and maturity reached in the year $3+$ age class (Fig. 3; Pusey et al. 2004):

$$
\operatorname{age}(\text { days })=94.252 \times e^{\text {length }(\mathrm{mm}) \times 0.0105} .
$$

Survival rates were calculated by regressing $\ln$ (abundance) age for each survey year. All slopes were linear, suggesting constant survival rates across age classes during the 2006-2010 surveys $(S=0.53 \pm 0.10$; mean \pm $\mathrm{SD})$. Per capita net reproduction was estimated from the ratio of (pre-spawning) $0+$ abundances relative to those of reproductive adult females in the previous year ( $F=$ $6.60 \pm 1.64$; mean \pm SD). Reproductive individuals were restricted to year $3+$ age classes (Pusey et al. 2004), and reproductive output was assumed equal across all age classes. In reality, fecundity will vary with the size of the individual, but by how much is not certain from available data. However, the similar mortality rate across age classes helped reduce the sensitivity of the results to this simplification.

Dispersal.-Dispersal rates were derived from acoustic tracking of juvenile and adult fish movement over the $2007 / 2008$ and 2008/2009 wet seasons. A total of 80 golden perch were tagged with acoustic tags (V7-4L$69 \mathrm{KHz}$, Vemco, Nova Scotia, Canada), and their

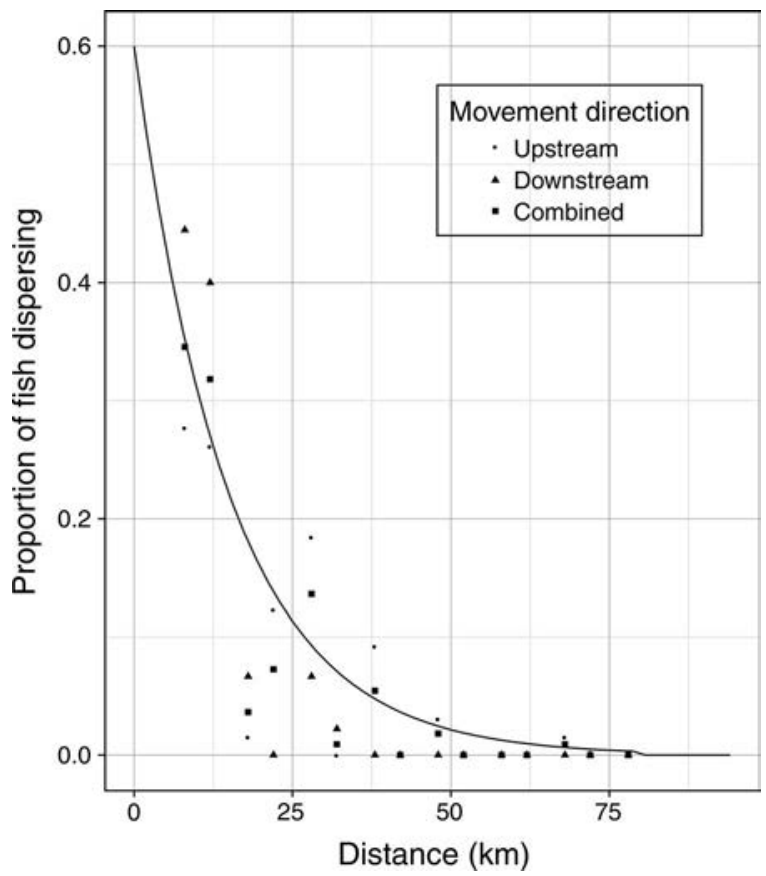

FIG. 3. Plot showing the proportion of tagged golden perch that moved upstream and downstream separately and when combined. The dispersal kernel fit to the data is indicated by the solid black line. 
movements recorded using a network of 17 listening stations (VR2W, Vemco, Nova Scotia, Canada) installed throughout a $\sim 85 \mathrm{~km}$ reach of the Moonie River, which encompassed 15 semipermanent waterholes. Dispersal in the model refers to the proportion of a population in one waterhole taking up residence in a different waterhole in the next year. The flow patterns of the survey years from 2007 to 2010 displayed contrasting event numbers and seasonality of flows, so that dispersal parameters were calculated based on the maximum distance of movements of tagged fish during a single flow event between waterholes. These generally occurred on the first flow events of a season. Tag-loss rates were highest in the month after tagging, generally before a flow event, and individuals disappearing from the pool of tagged fish were not included in the calculation of dispersal rate. Mortality was assumed equal for moving and resident fish. Return migrations were observed, but appeared to be contingent on suitable late season or winter flow events and were not modeled as independent dispersal events. Instead, it was assumed that the maximum distance travelled from the waterhole of origin was the most likely indicator of waterhole recolonization potential and gene flow between populations (J. Marshall et al., unpublished data). The acoustic tracking data suggested fish moved in an upstream and downstream direction at approximately equal rates, with the frequency of movement of individual fish decaying exponentially as a function of distance from the tagging location (Fig. 3). The proportion of individuals dispersing between each population pair $\left(M_{i j}\right)$ was estimated on the basis of an exponential (stream) distance decay function, with an additional constraint on maximum dispersal distance ( $D_{\max }$; Eq. 2).

$$
\begin{aligned}
& M_{i j}=a \times \exp \left(-D_{i j}^{c} / b\right), \text { if } D \leq D_{\max } \\
& M_{i j}=0, \text { if } D>D_{\max }
\end{aligned}
$$

Specific parameter values for the fitted curve (Fig. 3) were $a=0.6, b=20, c=1.0$, and $D_{\max }=80$. Dispersal rates were allowed to randomly fluctuate by setting the coefficient of variation $(\mathrm{CV})$ for dispersal parameter equal to 0.20 . There was no density-dependent constraint on dispersal because opportunities for movement between waterholes only occurred during high-flow events when density-dependent factors are unlikely to be important (Arthington and Balcombe 2011). One aspect of dispersal that we do not consider is the potential movement of larvae away from their natal site. Golden perch larvae are known to drift downstream; however, we have little information on the distances travelled nor any evidence to suggest such movements lead to widespread mixing and/or recolonization of isolated waterholes. We thus focus on adult movement, which is well documented and occurs over larger scales than is likely for larval drift.

Carrying capacity.-Carrying capacity of individual waterholes is primarily a function of their size, which can fluctuate by orders of magnitude (and fall to zero) in successive years. While other factors, such as rates of primary and secondary production, prey accessibility, and habitat quality, may also vary (Arthington and Balcombe 2011), these were all considered subordinate to the effects of hydrologic variability and were not considered in the model. There are no experimental field data to indicate carrying capacity of these waterholes, but golden perch are widely stocked in impoundments and farm dams. We therefore used recommended maximum stocking rates for golden perch as a guide to carrying capacity; approximately $500 \mathrm{~kg} / \mathrm{ha}$ (Boyd 2006), which equates to $\sim 0.05 \mathrm{fish} / \mathrm{m}^{2}$ given an average body mass of $1 \mathrm{~kg}$. This density is consistent with maximum densities of $\sim 1000 \mathrm{~kg} / \mathrm{ha}$ of mature fish observed after extended periods of flooding and recruitment in several neighboring arid-zone rivers (Balcombe et al. 2007, Sternberg et al. 2011). The effect of density dependence on local populations was modeled as a simple ceiling function, in which vital rates were modified only once $k$ was reached. Because of their small size, $0+$ fish were excluded from population size estimates for the purposes of determining when to invoke density dependence in the model.

Assessing which vital rates (mortality, fecundity, or dispersal) are influenced by density dependence was another key step in developing the model. Sternberg et al. (2011) found only minor interannual variation in body condition of fish caught in the same fyke net surveys used here, and suggested that survival rates rather than fecundity are the primary factor affected by hydrology. However, fish densities during these surveys were well below the estimated carrying capacity, and survival was relatively stable across age classes. In addition, the interpretation made by Sternberg et al. (2011) arguably pertains more to the absence of a boom in postflood recruitment, when resource availability is high, than to the likely effects of resource limitation. There are also no published examples in which crowding (i.e., density-dependent) effects have been linked to the mortality of this species, suggesting the response to crowding may also be subtle. We therefore hypothesized instead that declines in body condition from crowding would be more likely to affect reproductive investment than the survival of adults. Thus, density dependence was modeled to reduce fecundity only.

\section{Environmental stochasticity}

Interannual variability.-The volume of waterholes varies in two important ways. First, individual waterholes differ substantially in their volume when full, and hence, in their maximum carrying capacity $k_{\max }$. Second, differences in the depth of each waterhole affect the rate at which they dry and how long they persist. Fifteen depth loggers installed in waterholes in the Moonie River from 2004 to 2006 showed that water-loss rates (corresponding to $\sim 0.01 \mathrm{~m} / \mathrm{d}$ ) are relatively constant throughout the dry season and among waterholes (Queensland Government, unpublished data). From this, 
TABLE 1. Summary of the scenarios examined, including the parameter values and their associated effects within the model.

\begin{tabular}{llcc}
\hline \hline Scenario disturbance & \multicolumn{1}{c}{ Scenario affected } & Levels & Effect \\
\hline Drought frequency & frequency of regional catastrophes & $0.05,0.10$ & $\begin{array}{c}\text { for shallow waterholes, } k=0 ; \text { for } \\
\text { deep waterholes, no effect } \\
\text { causes proportional reduction in } k \\
\text { (mean, SD) }\end{array}$ \\
Aridity $(\Delta \mathrm{CTF})$ & cease-to-flow $(\mathrm{CTF})$ duration & baseline, $+5 \%,+10 \%$ & $\begin{array}{c}\text { shallow waterholes; no effect; deep } \\
\text { waterholes, } k=0\end{array}$ \\
Local pumping & likelihood of local catastrophes & $0,0.01,0.05,0.10$ & .
\end{tabular}

a sequence of minimum annual waterhole volumes (and proportional habitat loss) was calculated on the basis of dry season duration and estimated reduction of waterhole area. This provided a sequence of annual $k$ values for each waterhole, which we based on the assumed carrying capacity of $0.05 \mathrm{fish} / \mathrm{m}^{2}$, from which waterhole specific values for $k_{\mathrm{avg}}$ and $k_{\mathrm{SD}}$ could be calculated. Because interannual hydrologic variability tends to affect all waterholes similarly, $k$ values were modeled as being strongly correlated within each time step $\left(r^{2}=\right.$ 0.8 ). The correlation among individual $k$ values was still set at $r^{2}<1.0$ to reflect the likely influence of local shading, waterhole shape, soil conditions, etc., on local habitat quality and hence, carrying capacity.

Extended dry periods (regional catastrophes).-Extreme dry spells, here termed droughts, were modeled as regional catastrophes within RAMAS. We used the frequency of droughts (identified as extreme dry spells) in the historical record as a basis for their frequency in the model. Droughts were modeled to occur randomly with a probability of 0.05 in the baseline scenario (i.e., with an average return interval of 20 years, as per the historical flow sequence; Fig. 2). Droughts directly affected population abundances by killing all fish in shallow waterholes, which dry out in drought years. In contrast, deep waterholes $(\sim 30 \%$ by number) persist even during drought and were modeled as resistant to drought impacts. Local populations within deep waterholes were affected only by interannual variability in $k$, which for these habitats never approached zero.

\section{Scenarios}

Several scenarios of altered runoff and threats to waterhole persistence from local pumping were explored. These focused on changes in carrying capacity caused by increased drought frequency (two scenarios), reduced runoff (three scenarios), and increased pumping (three scenarios) from permanent waterholes. These three factors were examined in a factorial design $(n=24$ scenarios in total; Table 1).

While there remains considerable uncertainty about future runoff trends in this region, we envisage these 24 scenarios effectively bracket the range of possible futures that might arise. They therefore help gauge potential threats to long-term population viability of golden perch that might arise as a result of changes in disturbance regimes (e.g., regional vs. local events) and thus, help to inform long-term management strategies.
Altered drought frequency.-Droughts are expected to become more frequent in the Murray-Darling Basin due to climate change, although the exact changes in frequency and intensity are difficult to predict (CSIRO 2008a). Drought frequency was arbitrarily doubled from its historical frequency to occur, on average, once every 10 years (i.e., with a probability of 0.10 in any single time step; Table 1). This increase was intentionally set slightly higher than the $80 \%$ increase in drought frequency for the east coast by 2070 predicted by Mpelasoka et al. (2008) to provide a conservative test of population sensitivity to changing drought frequency.

Decreased runoff and sedimentation.-Rainfall-runoff modeling suggests future runoff in the Moonie River catchment will decline by $\sim 10 \%$ (median), with worst case scenarios closer to a $20 \%$ reduction (CSIRO 2008b). Decreased runoff will increase the average period without flow each year, which will reduce the average carrying capacity of waterholes. However, because much of the runoff in the Moonie River occurs during floods, the predicted $20 \%$ reduction in runoff volume is unlikely to result in such marked increases in cease-to-flow-spell durations. Thus, two scenarios were examined; a $+5 \%$ and $+10 \%$ increase in cease-to-flow-spell duration. For each scenario, the change in carrying capacity was estimated on the basis of average changes in water-hole volume at the end of the shortened dry spell (Table 1).

Local pumping.- In contrast to climatic influences on waterhole persistence, the effects of pumping are primarily localized to individual waterholes and are more likely to affect large permanent waterholes than smaller ones that persist only in some years. The threats from local water extraction were modeled as the probability of individual waterholes being pumped dry (pumping likelihood, $\operatorname{Pr}=0.01,0.05$, and 0.10; Table 1). This refers to the risk that water extraction by pumps from isolated waterholes for irrigation or stock and domestic use could lead to the waterhole contracting substantially in size. Stock and domestic water use is a riparian land right in Queensland, and pumps for this use tend to be much more common along waterholes known to persist during droughts. While extraction for other purposes is regulated, the risks of overextraction (whether intentionally or from pumps accidentally being left on) are a concern. The effects of local and regional disturbances are thus orthogonal to one another in their impacts on deep vs. shallow waterholes. 
TABLE 2. Sensitivity analysis results.

\begin{tabular}{|c|c|c|c|c|c|}
\hline \multirow[b]{2}{*}{ Parameter } & \multirow[b]{2}{*}{ Direction } & \multirow[b]{2}{*}{$\begin{array}{l}\text { Average } \\
\text { rank }\end{array}$} & \multicolumn{3}{|c|}{ Relative influence } \\
\hline & & & $\begin{array}{l}\text { Relative } \\
\text { abundance }\end{array}$ & $\begin{array}{c}\text { Patch } \\
\text { occupancy }\end{array}$ & $\begin{array}{l}\text { Extinction } \\
\text { risk }\end{array}$ \\
\hline \multicolumn{6}{|l|}{ Carrying capacity } \\
\hline$k_{\text {mean }}$ & - & 3 & 0.22 & 0.09 & 0.02 \\
\hline$k_{\mathrm{SD}}$ & - & 6 & 0.31 & 0.07 & 0.01 \\
\hline \multicolumn{6}{|l|}{ Survivorship } \\
\hline$S_{\text {mean }}$ & - & 1 & 0.91 & 0.66 & 0.22 \\
\hline$S_{\mathrm{SD}}$ & - & 9 & 0.07 & 0.02 & 0.01 \\
\hline \multicolumn{6}{|l|}{ Fecundity } \\
\hline$F_{\text {mean }}$ & - & 2 & 0.34 & 0.12 & 0.02 \\
\hline$F_{\mathrm{SD}}$ & - & 7 & 0.07 & 0.01 & 0.01 \\
\hline \multicolumn{6}{|l|}{ Dispersal } \\
\hline$a$ & - & 12 & 0.04 & 0.00 & 0.01 \\
\hline$b$ & - & 11 & 0.04 & 0.00 & 0.01 \\
\hline$c$ & - & 7 & 0.09 & 0.04 & 0.01 \\
\hline$D$ & - & 9 & 0.07 & 0.01 & 0.01 \\
\hline $\mathrm{CV}$ & - & 9 & 0.10 & 0.05 & 0.00 \\
\hline \multicolumn{6}{|c|}{ Vital rates sample distribution } \\
\hline EV.norm & & 8 & 0.08 & 0.01 & 0.01 \\
\hline \multicolumn{6}{|l|}{ Correlation structure } \\
\hline FSk uncorrelated & & 10 & 0.03 & 0.01 & 0.01 \\
\hline No spatial correlation & & 8 & 0.12 & 0.03 & 0.00 \\
\hline
\end{tabular}

Notes: The relative influence of varying each parameter on the three summary metrics describes the largest effect after adjusting each of the model input parameters by $\pm 10 \%$. Direction indicates the direction of change that had the larger effect (i.e., + or - ), and the ranks are those relative to all other variables in the model. The top three ranked parameters are shown in bold. EV.norm is sampling vital rates from a log-normal, rather than normal, distribution; $a, b, c$, and $D$ are parameters in the dispersal function (see Eq. 2); CV is coefficient of variation in the dispersal parameter; and $F S k$ is the correlation among $F, S$, and $k$.

\section{Initial abundances and age structure}

Initial abundances and age structure were estimated on the basis of average densities and size/age-frequencies observed in field surveys over the period of 2006-2009 (S. Balcombe, unpublished data). However, to avoid any bias associated with these initial conditions, the first 10 years were treated as a burn-in period when running the models and ignored in the results.

\section{Model runs}

Population outcomes were examined over a 100-year time horizon. Each scenario was replicated 1000 times to establish the effects of demographic and environmental stochasticity. Vital rate parameters were sampled from a log-normal distribution and $S, F$, and $K$ were correlated at each time step. Model runs were described on the basis of average metapopulation abundance, terminal patch-occupancy rates, and cumulative extinction risk over the 100-year time horizon.

\section{Sensitivity analyses}

The sensitivity of the model to uncertainty in the various input parameters was assessed using a simple perturbation analysis (Regan et al. 2003), in which the model was rerun with each of the model parameters adjusted independently by $\pm 10 \%$ of the starting value.
Sensitivity was quantified in terms of the relative effects of each of these changes on each of the summary statistics. This approach highlights influential variables rather than trying to model the actual risks to populations that might arise if all values were adjusted simultaneously (e.g., from coincident reductions in survival and fecundity; Akçakaya et al. 2003).

\section{RESUlts}

\section{Population viability and model sensitivity}

Modeled population sizes varied dramatically through time in response to demographic and environmental stochasticity, but in spite of this temporal variability under baseline (current) conditions, population sizes never fell below the quasi-extinction threshold over the modeled time-horizon, and can be considered dynamic but stable over long timescales.

Sensitivity analysis showed survival rates to have the greatest effect overall on abundances (relative influence of 0.91 ), followed by mean fecundity $(0.34)$ and carrying capacity ( 0.22 ; Table 2$)$. Uncertainty in these (and other) parameters had a much greater influence on abundance than on patch occupancy and extinction risk (Table 2). The influence of dispersal and spatial correlation structure were relatively weak within the bounds of the model (Table 2). 


\section{Scenario impacts}

Population viability was largely unaffected by the decreases in carrying capacity associated with increased aridity, with only small changes in population size and patch occupancy and extinction risk largely unchanged $(\sim 0.114$; Fig. 4). In contrast, the effect of increased drought frequency was severe, with extinction risk doubled to 0.24 and average population size nearly halved from 5578 to 3004 (Fig. 4).

Local-pumping scenarios also had a strong influence on population viability. At pumping likelihoods of $\geq 0.05$, the population went extinct in nearly $50 \%$ ( $\mathrm{Pr}$ $\geq 0.452$ ) of the model runs (Fig. 4). The effect of pumping was exacerbated even further by increased drought frequency. For example, a pumping likelihood of 0.01 under the baseline model was associated with a $\operatorname{Pr}$ (extinction) of 0.162 , up from 0.114 under baseline climate conditions. With more frequent droughts, however, this level of pumping more than doubled extinction risk to 0.313. At higher levels of pumping ( $\mathrm{Pr}$ $=0.05$ and 0.10 ), population extinction risk became increasingly certain, particularly when combined with more frequent droughts (Fig. 4).

\section{Discussion}

The metapopulation concept has attracted considerable interest from stream ecologists working in hydrologically variable river systems (e.g., Gotelli and Taylor 1999, Fagan 2002, Magoulick and Kobza 2003). In dryland rivers in particular, the patchy and dynamic nature of refuge habitats and the role of dispersal have become central questions relating to population persistence (Labbe and Fausch 2000, Falke et al. 2010, Huey et al. 2011). However, most studies exploring the impacts of changing river flows on population viability in dryland rivers have sought to model habitat dynamics as a proxy for population dynamics, as has been the case for environmental flow studies more generally (Jager and Smith 2008, Shenton et al. 2012). These habitat models do not capture the interactions between habitat loss and changing demographic rates, nor internal demographic feedbacks, even though such dynamics can strongly influence regional persistence (Hanski 1998). The modeling presented here is a tractable means of assessing the effects, not only of more frequent and intense disturbances, but also the effects of a novel disturbance (i.e., the periodic loss of individual refuges). It is also one of the few studies exploring the combined effects of disturbance frequency and intensity on population and landscape dynamics in real-world systems.

\section{Baseline predictions and model sensitivity}

One of the most striking features of dryland rivers is the role of temporal environmental variability in driving habitat availability and hence, survival rates (Bunn et al. 2006). Indeed, survival rates were observed to exert more than twice the influence of any other variable in terms of model sensitivity (Table 2), largely because of high mortality associated with dry years. In particular, stochastic sequences of dry years, in which droughts occurred in quick succession, reduced population sizes to low numbers, at which point they became exposed to demographic uncertainty and potential Allee effects. In general, although extinction risk under baseline conditions was low, the model predicted that successive drought sequences could still give rise to population extinction. Conversely, high abundances were predicted to occur following successive wet years, with these periods of growth effectively buffering the population during periods of drought.

Connectivity among refuges also plays a critical role in sustaining populations in fragmented landscapes (Hanski 1998), including for desert fishes (Meffe and Vrijenhoek 1988, Vrijenhoek 1998). In a recent study of the genetic structure of fish populations in the Moonie River, Huey et al. (2011) concluded that, overall, golden perch populations are highly connected by dispersal, but that periodic bottlenecks from waterhole drying have imparted some spatial genetic structure via drift. They were unable to determine the means by which gene flow occurs, whether by stepping-stone or long-distance dispersal, due to the absence of migration-drift equilibrium, which is required for making such inferences.

In contrast, direct observation of fish movement rates revealed a rapid decline in colonization rates as a function of distance from the source population (Fig. 3), suggesting that connectivity of relatively isolated populations is likely to arise via intermediate stepping stones, a pattern of movement that once again is widely observed among fish populations (Johnston 2000, Jackson et al. 2001). An implication of this is that successful colonization events will become less likely, and (presumably therefore) extirpation rates will increase as pools become more isolated, for example, due to local habitat loss or increased aridity.

\section{Scenario outcomes}

Comparisons among the different scenarios revealed two important findings. First, localized loss of normally permanent refuge habitats would appear to pose a significant threat to population viability even when some refuges persist in every year. This result reflects a classic situation arising in unstable metapopulations, where rates of local recolonization are insufficient to keep pace with rates of local extinction, which eventually leads to extinction of the regional population (Hanski 1998). A critical observation is that in many model runs, populations continued to persist for a considerable period of time even when pumping rates were high (Fig. 5). This means that long-term extinction risk may be very hard to discern from short-term monitoring programs. For example, even under the most extreme scenarios modeled (high frequency and intensity of local and regional disturbances), populations still continued to persist (on average) for $50+$ years, and in reality, 

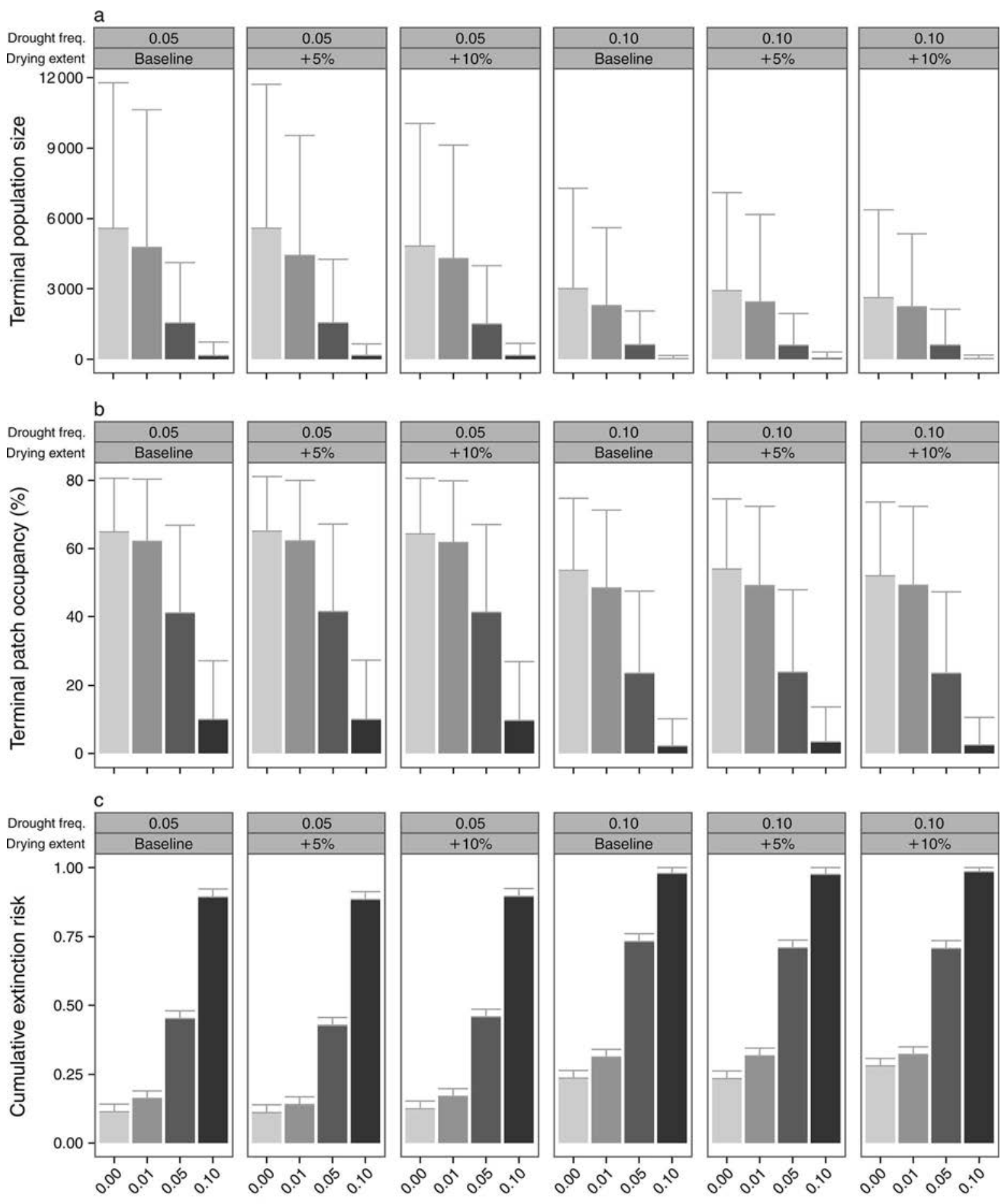

\section{Pumping likelihood}

FIG. 4. Bar graphs summarizing scenario outcomes of (a) terminal population size (number of golden perch), (b) terminal patch occupancy (percentage of waterholes occupied), and (c) cumulative extinction risk (risk of extinction of golden perch over the $100 \mathrm{yr}$ modeled). Individual scenarios are indicated (boxes at the top of the diagram) at two levels of drought frequency and three levels of drying extent (change in dry spell duration) for four levels of pumping likelihood. Error bars are SD in (a, b) and upper 95th percentile in (c). 


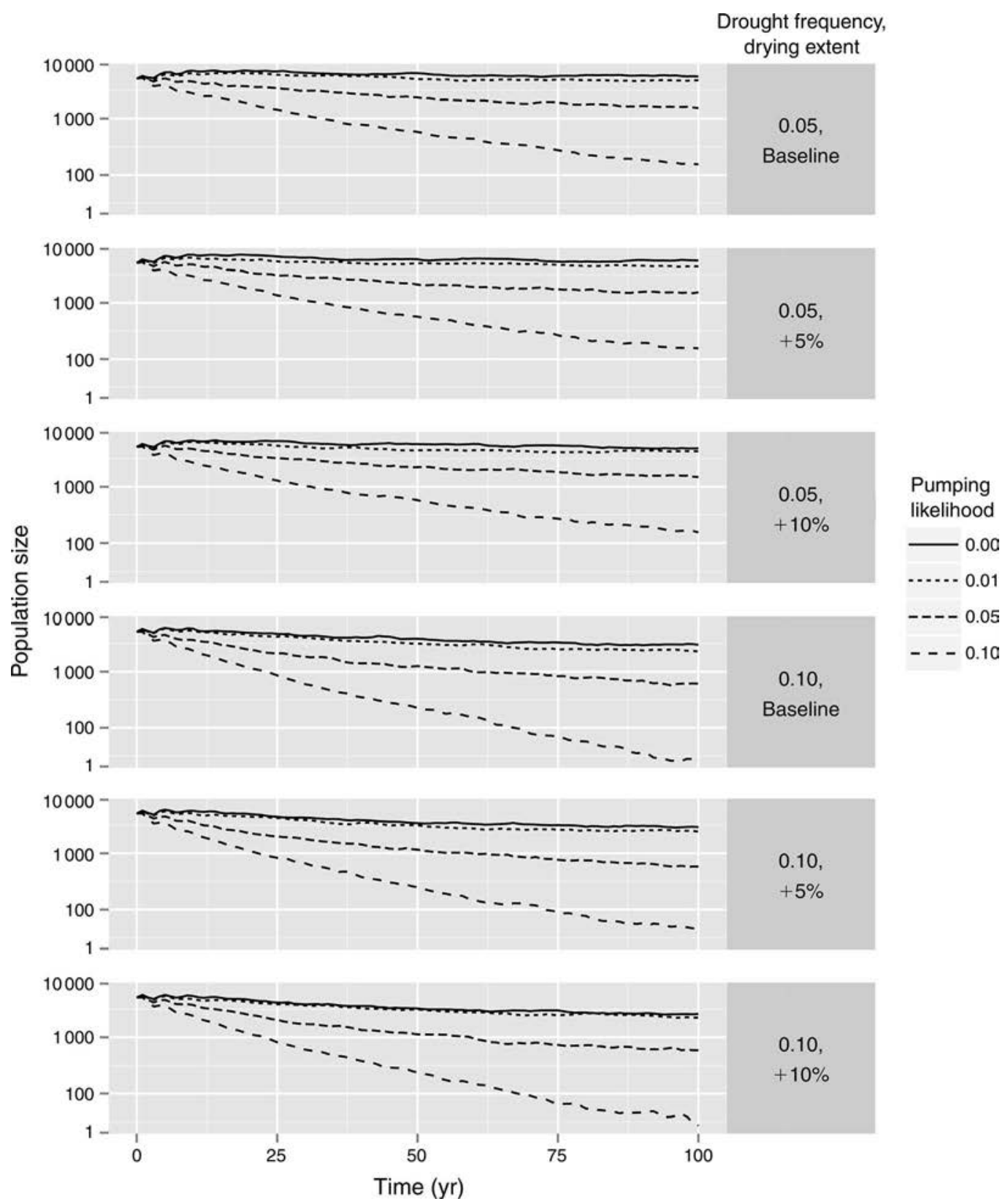

FIG. 5. Time series illustrating the average population trajectory under each of the modeled scenarios. Individual plots represent separate drought/aridity scenarios, with individual lines on each plot showing the effects of local disturbance through pumping.

long-term declines would be further masked by high interannual variability. Collectively, these results suggest that extinction debt (sensu Tilman et al. 1994), in which extinction is time-delayed but deterministic, may be high for desert fishes.

We also found that the effect of frequent local disturbances was high relative to that from regional disturbances. In a theoretical study, Wilcox et al. (2006) found varying effects of frequency and intensity, depending on synchrony of patch dynamics. It is thus likely that our findings reflect the higher modeled intensity of local disturbances relative to regional disturbance and thus, would be expected to vary among systems based on the nature of the disturbance regime and related patch dynamics (Wilcox et al. 2006).

The second key finding from the scenario comparisons was that even a relatively minor increase in the likelihood of local disturbance caused a large increase in extinction risk, and this response was strongly nonlinear as the likelihood of local disturbances was increased. This result is not in itself entirely surprising, as indeed there are many examples from both theoretical and 


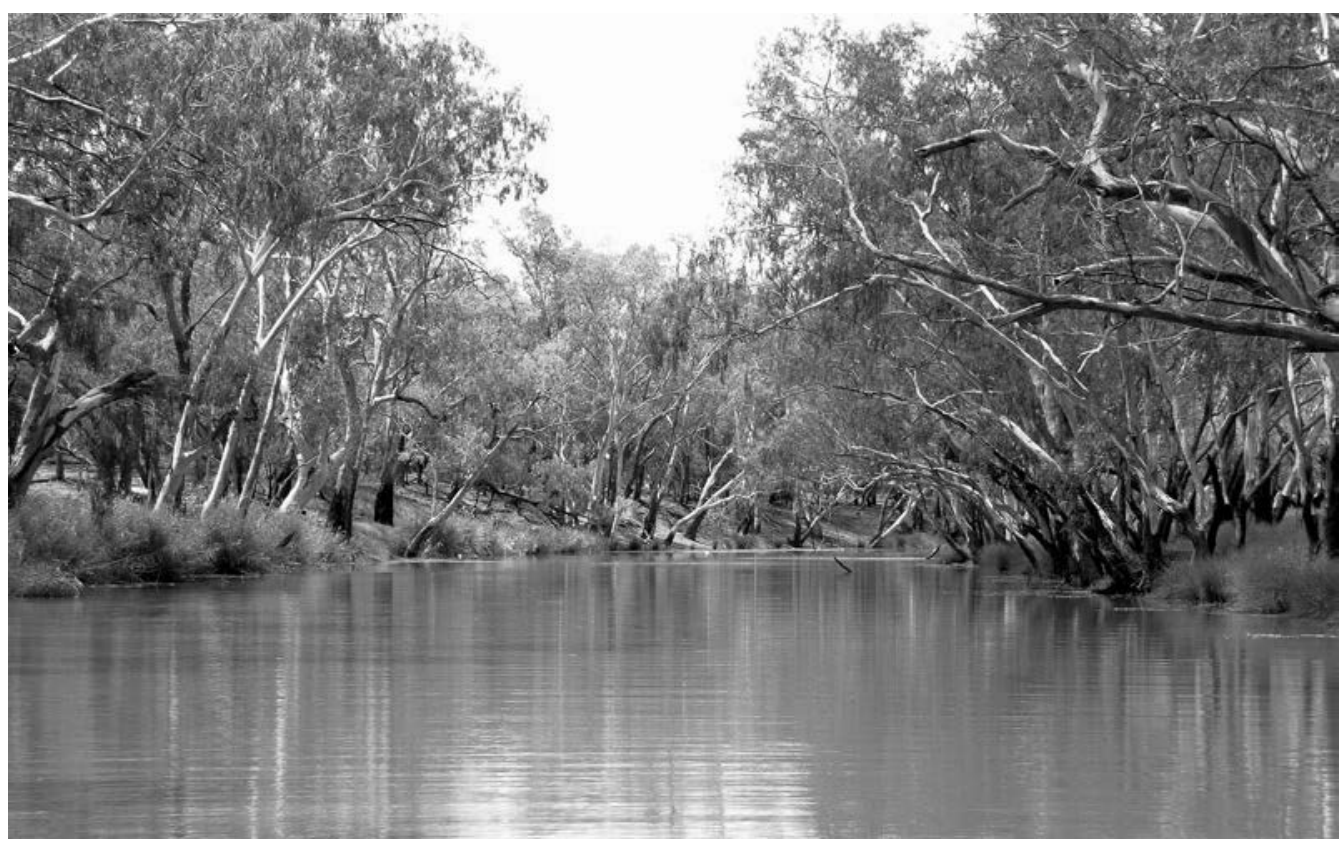

Plate 1. A large semi-permanent waterhole on the Moonie River (Australia) early in the dry season. Waterholes such as this are important refuges but are also a source of water for off-channel human uses. Photo credit: J. C. Marshall.

empirical research in which populations display strongly nonlinear dynamics in response to changes in vital rates and connectivity among habitat patches (e.g., May 1974, Hanski 1998). The important take-home message is that even seemingly stable populations may reach previously unidentified tipping points along gradients of disturbance frequency, beyond which extinction risk becomes very high (Wilcox et al. 2006).

\section{Management implications}

There has been a long-standing awareness of the threats to desert fishes from water resource development and other anthropogenic pressures, but also of the difficulties in trying to predict extinction risks among species for whom habitats periodically expand and contract (Minckley and Deacon 1968). Over the last decade, threats from increasing aridity and water resource development have generated renewed interest at a global level (e.g., see the UN's Decade for Deserts and Desertification Program, 2010-2020). Impacts from anthropogenic pressures on desert rivers, and fishes in particular, have received greatest attention in areas such as central and southwestern USA (Meffe and Vrijenhoek 1988, Fagan et al. 2005), southwestern Europe (Magalhães et al. 2002), and Australia (Unmack 2001, Balcombe et al. 2006). However, despite this increased focus, a challenge for evaluating longer-term sustainability issues is that much of the existing research on these ecosystems is observational or relatively short term, and there are few examples in which explicit predictions have been (or can be) made regarding the likely long-term consequences of altered disturbance regimes. As our research shows, this represents a critical knowledge gap for the management and conservation of dryland rivers (Propst et al. 2008).

Persistence of fish in our study system depends on the presence of deep, refuge waterholes that persist even during severe droughts. Such habitats are prone to surface and groundwater extraction (e.g., Bunn et al. 2006, Falke et al. 2010), and indeed, water resource development could pose a significant threat to longerterm population viability of fishes in this system if not adequately managed. Potential strategies to alleviate these risks are to first limit the number of waterholes exposed to additional anthropogenic drawdown. We assumed that pools are not fed by near-surface groundwater and thus, that the effects of local pumping remain localized. In areas with highly connected surface-groundwater systems, this assumption may not hold (e.g., Labbe and Fausch 2000). Understanding the influence of water resource development on coupled surface-groundwater systems and the role of these interactions in maintaining aquatic refuges remains a poorly studied area of research (Fausch et al. 2002). While there are some examples in which detailed water balance models have been developed for specific planning areas (e.g., Falke et al. 2010), it may be necessary to also consider proxy methods for predicting waterhole persistence when working over much larger spatial scales (e.g., see Hermoso et al. 2012).

An important question is how our work on this singlespecies system can inform the management of other species, including those for which there are limited data. Perhaps the first point is to emphasize the heuristic value 
of population viability analysis (PVA) models in identifying and beginning to quantify the sorts of threats that might previously have been overlooked, even for well-studied species. Secondly, the PVA process provides a structured way of organizing information that can aid in framing problems and system understanding ("the facilitator") and in helping to compare risks ("the stockbroker"; Burgman and Possingham 2000). Equally important is to recognize the risks of overreliance on PVA as a sole decision making tool ("the loaded gun"; Burgman and Possingham 2000). Where limited information is available for particular species, it may still be possible to gather sufficient data to develop models capable of distinguishing the potential response of species with different life-histories (e.g., Yen et al. 2013) and to use those models to develop testable hypotheses that can help fill specific knowledge gaps. For example, above all else, our work on golden perch highlights the potential for extinction debt to mask seemingly certain extinction from this system under some scenarios, thereby highlighting the importance of considering persistence over relatively longer time-scales than can typically be achieved as part of isolated field studies and of thinking carefully about management actions that influence the historic disturbance regime.

In summary, while a number of studies have highlighted threats to dryland and desert river fishes from anthropogenic pressures (e.g., Oakes et al. 2005, Bunn et al. 2006, Falke et al. 2010), these primarily describe hydrologic changes or expected shifts in distribution patterns rather than modeling the actual mechanisms that regulate fish abundances, such as survival and movement (Oakes et al. 2005). This study helps address this important knowledge gap using a large-bodied, apex fish predator, golden perch, as a model species. The study both highlights the potential threat from anthropogenic influences to the viability of this species in the study system, and also demonstrates a novel application of population viability modeling to examine the effects of changing landscape dynamics (i.e., refuge habitat availability) on population persistence in dryland rivers. Such an approach could readily be applied to biota inhabiting highly dynamic environments in other parts of the world.

\section{ACKNOWLEDGMENTS}

We thank A. Arthington, D. Sternberg, J. Huey, S. Linke, D. O'Mahoney, and J. Fawcett, who helped with various aspects of the fieldwork. P. Brownhalls, J. Coysh, J. Greet, C. Todd, J. White, S. Wenger, and three anonymous reviewers who provided helpful comments on an earlier version of the manuscript. W. Shenton and C. Todd also provided useful discussions about population modeling. The research was funded in part by eWater CRC (Cooperative Research Centre). N. Bond developed the population model and wrote the manuscript. N. Menke contributed the fish length-age regression and analyzed the movement data. D. Crook, J. Marshall, and J. Lobegeiger oversaw the acoustic telemetry, S. Balcombe conducted the population surveys, and J. Marshall, N. Menke, and J. Lobegeiger carried out the waterhole mapping and water-loss modeling.

\section{Literature Cited}

Akçakaya, H. R. 2005. RAMAS Metapop: viability analysis for stage-structured metapopulations. Version 5.0. Applied Biomathematics, Setauket, New York, USA.

Akçakaya, H. R., J. Atwood, and D. Breininger. 2003. Metapopulation dynamics of the California least tern. Journal of Wildlife Management 67:829-842.

Akçakaya, H. R., M. A. Burgman, and L. R. Ginzburg. 1999. Applied population ecology: principles and computer exercises using RAMAS EcoLab 2.0. Sinauer Associates, Sunderland, Massachusetts, USA.

Arthington, A. H., and S. R. Balcombe. 2011. Extreme flow variability and the "boom and bust" ecology of fish in aridzone floodplain rivers: a case history with implications for environmental flows, conservation and management. Ecohydrology 4:708-720.

Arthington, A. H., S. R. Balcombe, G. A. Wilson, M. C Thoms, and J. Marshall. 2005. Spatial and temporal variation in fish-assemblage structure in isolated waterholes during the 2001 dry season of an arid-zone floodplain river, Cooper Creek, Australia. Marine and Freshwater Research $56: 1-11$.

Balcombe, S. R., A. H. Arthington, N. D. Foster, M. C. Thoms, G. G. Wilson, and S. E. Bunn. 2006. Fish assemblages of an Australian dryland river: abundance, assemblage structure and recruitment patterns in the Warrego River, Murray-Darling Basin. Marine and Freshwater Research 57:619.

Balcombe, S. R., S. E. Bunn, A. H. Arthington, J. H. Fawcett, F. J. McKenzie-Smith, and A. Wright. 2007. Fish larvae, growth and biomass relationships in an Australian arid zone river: links between floodplains and waterholes. Freshwater Biology 52:2385-2398.

Boyd, S. 2006. Fish in farm dams. New South Wales Department of Primary Industries, Port Stephens, Australia.

Bunn, S. E., M. Thoms, S. Hamilton, and S. Capon. 2006. Flow variability in dryland rivers: boom, bust and the bits in between. River Research and Applications 22:179-186.

Burgman, M., and H. Possingham. 2000. Population viability analysis for conservation: the good, the bad and the undescribed. Pages 97-112 in A. G. Young and G. M. Clarke, editors. Genetics, demography and viability of fragmented populations. Cambridge University Press, London, UK.

Crook, D. A., P. Reich, N. R. Bond, D. McMaster, J. D. Koehn, and P. S. Lake. 2010. Using biological information to support proactive strategies for managing freshwater fish during drought. Marine and Freshwater Research 61:379387.

CSIRO. 2008a. Water availability in the Murray-Darling Basin. A report to the Australian government from the CSIRO Murray-Darling Basin Sustainable Yields Project. Commonwealth Scientific and Industrial Research Organisation, Canberra, Australia.

CSIRO. 2008b. Water availability in the Moonie. A report to the Australian government from the CSIRO Murray-Darling Basin Sustainable Yields Project. Commonwealth Scientific and Industrial Research Organisation, Canberra, Australia.

Dai, A. 2011. Drought under global warming: a review. WIREs Climate Change 2:45-65.

Elkin, C. M., and H. Possingham. 2008. The role of landscapedependent disturbance and dispersal in metapopulation persistence. American Naturalist 172:563-575.

Fagan, W. F. 2002. Connectivity, fragmentation, and extinction risk in dendritic metapopulations. Ecology 83:3243-3249.

Fagan, W. F., C. Aumann, C. M. Kennedy, and P. J. Unmack. 2005. Rarity, fragmentation, and the scale dependence of extinction risk in desert fishes. Ecology 86:34-41.

Falke, J. A., K. D. Fausch, R. Magelky, A. Aldred, D. S. Durnford, L. K. Riley, and R. Oad. 2010. The role of 
groundwater pumping and drought in shaping ecological futures for stream fishes in a dryland river basin of the western Great Plains, USA. Ecohydrology 4:682-697.

Fausch, K. D., C. Torgersen, and C. V. Baxter. 2002. Landscapes to riverscapes: bridging the gap between research and conservation of stream fishes. BioScience 52:483-498.

Gotelli, N., and C. Taylor. 1999. Testing metapopulation models with stream-fish assemblages. Evolutionary Ecology Research 1:835-845.

Hanski, I. 1998. Metapopulation dynamics. Nature 396:41-49.

Hermoso, V., D. P. Ward, and M. J. Kennard. 2012. Using water residency time to enhance spatio-temporal connectivity for conservation planning in seasonally dynamic freshwater ecosystems. Journal of Applied Ecology 49:1028-1035.

Huey, J. A., D. J. Schmidt, S. R. Balcombe, J. C. Marshall, and J. M. Hughes. 2011. High gene flow and metapopulation dynamics detected for three species in a dryland river system. Freshwater Biology 56:2378-2390.

Jackson, D. A., P. R. Peres-Neto, and J. D. Olden. 2001. What controls who is where in freshwater fish communities the roles of biotic, abiotic, and spatial factors. Canadian Journal of Fisheries and Aquatic Sciences 58:157-170.

Jager, H. I., and B. T. Smith. 2008. Sustainable reservoir operation: can we generate hydropower and preserve ecosystem values? River Research and Applications 24:340352.

Johnston, C. 2000. Movement patterns of imperiled blue shiners (Pisces: Cyprinidae) among habitat patches. Ecology of Freshwater Fish 9:170-176.

Labbe, T. R., and K. D. Fausch. 2000. Dynamics of intermittent stream habitat regulate persistence of a threatened fish at multiple scales. Ecological Applications 10:17741791.

Magalhães, M. F., P. Beja, C. Canas, and M. J. CollaresPereira. 2002. Functional heterogeneity of dry-season fish refugia across a Mediterranean catchment: the role of habitat and predation. Freshwater Biology 47:1919-1934.

Magoulick, D. D., and R. M. Kobza. 2003. The role of refugia for fishes during drought: a review and synthesis. Freshwater Biology 48:1186-1198.

May, R. 1974. Biological populations with nonoverlapping generations - stable points, stable cycles, and chaos. Science 186:645-647.

Meffe, G. K., and R. C. Vrijenhoek. 1988. Conservation genetics in the management of desert fishes. Conservation Biology 2:157-169.

Minckley, W. L., and J. E. Deacon. 1968. Southwestern fishes and the enigma of "endangered species." Science 159:14241432.

Mpelasoka, F., K. Hennessy, R. Jones, and B. Bates. 2008. Comparison of suitable drought indices for climate change impacts assessment over Australia towards resource management. International Journal of Climatology 28:12831292.

Oakes, R., K. B. Gido, J. A. Falke, J. D. Olden, and B. Brock. 2005. Modelling of stream fishes in the Great Plains, USA. Ecology of Freshwater Fish 14:361-374.
Perry, G. L. W., and N. R. Bond. 2009. Spatially explicit modeling of habitat dynamics and fish population persistence in an intermittent lowland stream. Ecological Applications 19:731-746.

Propst, D. L., K. B. Gido, and J. A. Stefferud. 2008. Natural flow regimes, nonnative fishes, and native fish persistence in aridland river systems. Ecological Applications 18:1236-1252.

Puckridge, J. T., F. Sheldon, K. F. Walker, and A. J. Boulton. 1998. Flow variability and the ecology of large rivers. Marine and Freshwater Research 49:55-72.

Puckridge, J. T., K. F. Walker, and J. F. Costelloe. 2000. Hydrological persistence and the ecology of dryland rivers. Regulated Rivers Research and Management 16:385-402.

Pusey, B., M. J. Kennard, and A. Arthington. 2004. Freshwater fishes of north-eastern Australia. CSIRO Publishing, Collingwood, Victoria, Australia.

Regan, H. M., H. R. Akçakaya, S. Ferson, K. V. Root, S. Carroll, and L. R. Ginzburg. 2003. Treatments of uncertainty and variability in ecological risk assessment of single-species populations. Human and Ecological Risk Assessment 9:889906.

Root, K. V. 1998. Evaluating the effects of habitat quality, connectivity, and catastrophes on a threatened species. Ecological Applications 8:854-865.

Sheldon, F., A. J. Boulton, and J. T. Puckridge. 2002. Conservation value of variable connectivity: aquatic invertebrate assemblages of channel and floodplain habitats of a central Australian arid-zone river, Cooper Creek. Biological Conservation 103:13-31.

Shenton, W., N. R. Bond, J. D. L. Yen, and R. Mac Nally. 2012. Putting the "ecology" into environmental flows: ecological dynamics and demographic modelling. Environmental Management 50:1-10.

Sternberg, D., S. R. Balcombe, J. C. Marshall, J. S. Lobegeiger, and A. H. Arthington. 2011. Subtle "boom and bust" response of Macquaria ambigua to flooding in an Australian dryland river. Environmental Biology of Fishes 93:95-104.

Tilman, D., R. M. May, C. L. Lehman, and M. A. Nowak. 1994. Habitat destruction and the extinction debt. Nature 371:65-66.

Unmack, P. J. 2001. Fish persistence and fluvial geomorphology in central Australia. Journal of Arid Environments 49:653-669.

Vrijenhoek, R. C. 1998. Conservation genetics of freshwater fish. Journal of Fish Biology 53:394-412.

Walker, K. F., F. Sheldon, and J. T. Puckridge. 2006. A perspective on dryland river ecosystems. Regulated Rivers Research and Management 11:85-104.

Wilcox, C., B. Cairns, and H. Possingham. 2006. The role of habitat disturbance and recovery in metapopulation persistence. Ecology 87:855-863.

Yen, J. D. L., N. R. Bond, W. Shenton, D. A. Spring, and R. Mac Nally. 2013. Identifying effective water-management strategies in variable climates using population dynamics models. Journal of Applied Ecology 50:691-701.

\section{Supplemental Material}

\section{Data Availability}

Data associated with this paper have been deposited in the Griffith University Data Repository: http://dx.doi.org/10.4225/01/ 549222 b0a4d24 